\title{
Lying behavior and activity during the transition period of clinically healthy grazing dairy cows
}

\author{
S. J. Hendriks, ${ }^{1 *}$ C. V. C. Phyn, ${ }^{2}$ S-A. Turner, ${ }^{2,3}$ K. M. Mueller, ${ }^{4}$ B. Kuhn-Sherlock, ${ }^{2}$ D. J. Donaghy, ${ }^{1}$ \\ J. M. Huzzey, ${ }^{5}$ and J. R. Roche ${ }^{2,6} \dagger$ \\ ${ }^{1}$ School of Agriculture and Environment, Massey University, Palmerston North 4442, New Zealand \\ ${ }^{2}$ DairyNZ Ltd., Hamilton 3240, New Zealand \\ ${ }^{3}$ Dairy Goat Co-operative, PO Box 1398, Hamilton 3240, New Zealand \\ ${ }^{4}$ School of Veterinary Sciences, Massey University, Palmerston North 4442, New Zealand \\ ${ }^{5}$ Department of Animal Science, California Polytechnic State University, San Luis Obispo, CA 93407 \\ ${ }^{6}$ School of Biological Sciences, University of Auckland, Private Bag 92019, Auckland 1142, New Zealand
}

\section{ABSTRACT}

Lying behavior and activity may provide useful information for the prediction of an imminent calving and the health of transition dairy cows; however, it is important first to understand what constitutes typical lying behavior and activity because this has not been defined for grazing dairy cows during the transition period. Our objective was to describe changes in lying behavior and activity in grazing dairy cows during the transition period using varying phenotypes typical of commercial dairy herds under grazing systems. Behavior data from IceTag or IceQube (IceRobotics, Edinburgh, Scotland) triaxial accelerometers were collected for 310 cow parities from multiparous, mixedage (mean \pm standard deviation; $4.5 \pm 1.65 \mathrm{yr}$ ), and mixed-breed [Holstein-Friesian (HF), $\mathrm{n}=216$; and $\mathrm{HF}$ $\times$ Jersey, $\mathrm{n}=94$ ] grazing dairy cows from 4 parent experiments. The IceTags or IceQubes captured lying and activity data during the transition period $(-21$ to $34 \mathrm{~d}$ relative to calving) to allow the calculation of daily lying time (h/d), daily lying bouts (LB; no./d), mean LB duration (min/bout), and the number of steps taken (steps/d). Lying behavior and activity were analyzed using a repeated measures ANOVA during 3 periods: $\operatorname{PRE}(-21$ to $-3 \mathrm{~d}$ ), POST ( 3 to $21 \mathrm{~d}$ ), and the day of calving (d 0). Lying time was lower on d $0(7.25 \mathrm{~h} / \mathrm{d})$ compared with PRE and POST lying times (10.3 and $8.58 \mathrm{~h} / \mathrm{d}$, respectively), with more frequent $\mathrm{LB}$ on $\mathrm{d} 0$ (12.9 no./d) compared with the PRE and POST daily LB (8.15 vs. 7.74 no./d). Cows took more steps POST (4,424 steps/d) compared with d 0 and PRE (4,105

Received November 26, 2018.

Accepted April 22, 2019.

*Corresponding author: s.hendriks@massey.ac.nz

$\dagger$ Current address: Ministry for Primary Industries, Wellington 6140, New Zealand. and 2,289 steps/d, respectively). Regression analysis determined that daily lying time decreased substantially from -3 to $0 \mathrm{~d}$ ( slope $=-1.03 \pm 0.07 \mathrm{~h} / \mathrm{d})$ and from -2 and $-1 \mathrm{~d}$ for daily $\mathrm{LB}$ (slope $=5.09 \pm 0.54$ no./d), which may be due to the calving event itself but also reflect restlessness. Daily lying time, daily LB, LB duration, and number of steps taken were substantially altered at the time of the calving event in grazing dairy cows. Cows were more active, spent less time lying, and took more steps postcalving compared with precalving, and it appears that this behavior may largely be due to activity associated with twice daily milking. Mean lying behavior and activity measures were more highly variable across individuals than across groups. Information available via activity monitors may contribute to the improvement of individual management of transition dairy cows, and this research provides a benchmark for typical changes in behavior during the transition period in grazing systems.

Key words: activity monitor, behavior, grazing cow, pasture

\section{INTRODUCTION}

Lying is an important component of cow comfort and an indicator of welfare (Munksgaard and Simonsen, 1996). In housed systems, lying behavior has recently been recognized as an early indicator of health problems (Weary et al., 2009) and is also of interest in grazing systems for the improved management of individual dairy cows (Drackley, 1999). Technology has recently become available that allows lying behavior and activity to be easily quantified in grazing systems (Borchers and Bewley, 2015). Quantitative research that focuses on defining changes in the behavior of healthy cows is an important consideration when using behavior as an indicator of illness or welfare (Maselyne et al., 2017; Neave et al., 2017). However, there is a lack of detailed information on changes in lying behavior and activity 
of grazing dairy cows, particularly during the transition period.

The transition period of dairy cows is the 6 -wk period encompassing calving (Grummer, 1995; Drackley, 1999), during which dairy cows must manage the exponential growth of the fetus, overcome the event of calving, and adapt to the increased physiological, metabolic, and nutritional demands imposed by the start of lactation (Grummer, 1995; Drackley, 1999; Roche et al., 2013). Cows are exposed to a multitude of management-related changes (Sepúlveda-Varas et al., 2014), and these changes in addition to physiological and cow factors can result in poor adaptation associated with increased health risk (Drackley, 1999; Roche et al., 2013). Understanding the effects of cow, physiological, and management factors on lying behavior and activity will improve our understanding of factors to take into consideration when using behavior as an indicator of health or welfare and help producers optimize the treatment of cows (Bewley et al., 2010).

Behaviors expressed may differ due to cow factors; limited studies have investigated both pre- and postcalving lying behavior and activity and the influence of breed, parity, and BCS in grazing dairy cows. Stone et al. (2017) first evaluated differences among dairy cattle breeds under housing conditions. No effect of breed was observed when comparing Holstein-Friesian (HF), Jersey $(\mathbf{J})$, and $\mathrm{HF} \times \mathrm{J}$ dairy cattle breeds for lying behavior. One study has reported increased lying time with parity in grazing cows (Sepúlveda-Varas et al., 2014), and the findings of Calderon and Cook, (2011) in housed cows support this. However, others have reported no effect of parity on lying behavior in housed cows (Bewley et al., 2010). One study in late lactation grazing cows reported a decrease in lying time with decreasing BCS (Matthews et al., 2012). In contrast, Bewley et al. (2010) reported BCS category did not affect lying behavior in housed cows in early lactation. To our knowledge, further studies have not been undertaken to investigate the effect of breed, parity, and BCS on lying behavior in grazing cows, and information in this area is lacking.

Behaviors expressed may also differ due to physiological factors and management (Kok et al., 2017). Physiological and management factors can constrain the time budgets of cows and drive differences in time required lying, feeding, ruminating, and in lactating cows being milked (Jensen et al., 2005; Norring et al., 2012). Physiological state due to the change from dry to lactating state is likely to be a large determinant of behavior immediately pre- and postcalving. However, management (e.g., housed versus grazing) may influence the magnitude of the change. Lying behavior has been investigated in transition cows in confinement and on pasture. A study evaluating the postcalving lying behavior of a group of grazing cows highlighted differences in daily lying times when compared with lying times reported in housed cows, and it was speculated that this could be due to external factors such as feed accessibility and time spent walking to and from the milking parlor (Sepúlveda-Varas et al., 2014). Only 2 studies (Black and Krawczel, 2016; Rice et al., 2017) have investigated the precalving lying behavior of dairy cows on pasture, but these animals were only moved onto pasture before calving as they were usually housed and fed TMR and they were kept in small groups $(2-6$ cows). Therefore, the results of these studies may not accurately reflect typical behavior of grazing cows where animals are required to meet energy requirements from pasture, have longer walking distances, and are typically kept in larger groups (Beggs et al., 2018). To our knowledge, cow, physiological, and management factors that influence dairy cow lying behavior and activity encompassing the 6-wk transition period and calving event have not been investigated in a substantial population of animals in grazing dairy systems. Our objectives were to determine (1) the daily and 24-hourly changes in lying behavior and activity, and (2) the associations between cow factors and lying behavior and activity, during the transition period of grazing dairy cows.

\section{MATERIALS AND METHODS}

\section{Animal Handling, Experimental Design, and Management}

The Ruakura Animal Ethics Committee (Hamilton, New Zealand) approved all animal manipulations in accordance with the New Zealand Animal Welfare Act (Ministry for Primary Industries, 1999). Data for the present study were obtained from 4 separate parent experiments [BCS, feed, zeolite, and nonsteroidal anti-inflammatory drugs (NSAID); Supplemental Table S1; https://doi.org/10.3168/jds.2018-16045]. These experiments were undertaken across 4 seasons and 3 locations: between June and September in 2012, 2013, 2014, and 2016 (Supplemental Table S1; https:/ /doi.org/10.3168/jds.2018-16045). Cows were managed as a typical commercial herd of grazing cows under a spring-calving system, where the herds are managed on pasture throughout the transition period and rotationally grazed as described by Roche et al. (2005). The area allocated per cow precalving $\left(23-60 \mathrm{~m}^{2} / \mathrm{cow}\right)$ was typical of grazing systems and increased with time in all studies. Increasing pasture growth rates and pasture availability alongside increased feed demand as the seasonal calving period extends from winter to spring 
allowed the allocations of fresh pasture to increase by increasing the area allocated per cow, and supplementary feed allocations were reduced (Roche et al., 2009). Nonlactating cows and lactating cows received allocations of fresh pasture daily in all studies. Fresh pasture offered was a mixture of perennial ryegrass ( $\mathrm{Lo}$ lium perenne L.) and white clover (Trifolium repens L.) pasture. Nonlactating cows received pasture silage in the BCS and feed studies, maize silage in the BCS and zeolite studies, and palm kernel expeller in the BCS study as supplementary feeds. Lactating cows received pasture silage in all studies, and maize silage in the NSAID and BCS studies as supplementary feeds. Cows were offered on average 1.6 to $3.0 \mathrm{~kg}$ of $\mathrm{DM} / \mathrm{cow}$ per day as supplementary feeds, and cows consumed a diet that was at least $75 \%$ fresh pasture across all 4 studies. During the postcalving period, cows were milked twice daily in a rotary parlor. Total time spent standing and walking to and from the milking parlor ranged from $\sim 40$ to $90 \mathrm{~min} / \mathrm{d}$.

\section{Cow Descriptions, Data Collection, and Analysis}

Behavioral parameters were extracted for analysis from the 4 parent experiments using subsets of cows fitted with electronic activity monitors. Of 380 total cow parities available in the 4 experiments, data from 310 cow parities were selected for analysis. Multiparous mixed-age [mean \pm standard deviation (SD); $4.5 \pm$ $1.65 \mathrm{yr}]$ and mixed-breed $(\mathrm{HF} ; \mathrm{n}=216$ and $\mathrm{HF} \times \mathrm{J}$; $\mathrm{n}=94$ ) cows were selected. All cows included in the study were multiparous (i.e., approaching their 2 nd or greater parity at the time of calving). The remaining 69 cow parities were removed from analysis due to invalid data (e.g., activity monitor errors, incomplete data, or cows removed from the study). One $\mathrm{J}$ cow was removed to avoid a breed group of $\mathrm{n}=1$. Behavioral data were available for the period -21 to $34 \mathrm{~d}$, relative to the day of calving $(0 \mathrm{~d})$ for the analysis.

\section{Behavioral Data and Editing}

Behavioral data were recorded using an electronic activity monitor. Each cow was fitted with an IceTag or IceQube (IceRobotics, Edinburgh, Scotland) on the lateral side of a hind leg. Both of these activity monitors use triaxial accelerometers to characterize activity, and weigh $190 \mathrm{~g}$ (IceQube; $96 \times 81 \times 31 \mathrm{~mm}$ ) and 197 $\mathrm{g}$ (IceTag; $65 \times 60 \times 30 \mathrm{~mm})$; both were contained within plastic housing. The IceQube and IceTag devices capture data at a frequency of 4 and $16 \mathrm{~Hz}$, respectively (IceRobotics Ltd., 2017).

Behavioral parameters were measured through the position of the 3 axes of the activity monitor and these data were stored in the memory of the device (60-d onboard storage capacity). Lying time is recorded when the orientation of the hind leg is horizontal and the step count is measured by the number of times the animal lifts its leg up and places it back down again. A lying bout (LB) is defined as the period between the activity monitor changing from vertical to horizontal back to vertical.

Data were removed and downloaded using the IceManager 2010 software (IceRobotics) to generate 2 summary files per cow. One file consisted of recording lying time (s), standing time (s), and number of steps for 1- and 15-min epoch intervals, for the IceTag and IceQube, respectively. This summary output was then used to calculate daily lying time (h/d) and number of steps (steps/d) for each cow. The IceTag and IceQube have been validated against visual observations for summarizing daily lying times (Mattachini et al., 2013; Borchers et al., 2016). The other file contained all recorded LB, with a start date, start time (hh:mm: $\mathrm{ss}$ ), and duration (s) and was used to calculated transitional behavior [e.g., daily LB (no./d) and mean LB duration ( $\mathrm{min} /$ bout)].

From the output data sets, the sampling dates for each individual cow were assigned an experimental day relative to the day of calving $(0 \mathrm{~d})$. The data recorded on the day that the data loggers were removed or fitted to the cows were not included in the analysis and outliers were removed only where the data point could be explained by an incorrect logger recording (i.e., $<24 \mathrm{~h}$ of total activity recorded within day or total lying time equal to $24 \mathrm{~h}$ ). These transformed data sets were the basis of subsequent analyses.

\section{Milk, BCS, BW, Breed, and Production}

Cows were milked twice daily and milk yield was measured daily from 1 to 35 DIM. Milk was sampled weekly on consecutive afternoon and morning milkings and a composite sample was analyzed for milk composition by infrared analysis (FT120, Foss Electric, Hillerød, Denmark). Energy-corrected milk yield was calculated as by Nielsen et al. (2009):

$$
\begin{gathered}
\mathrm{kg} \text { of } \mathrm{ECM}=[\mathrm{kg} \text { of milk } \\
\times(383 \times \text { fat } \%+242 \times \operatorname{protein} \%+780.8)] / 3,140 .
\end{gathered}
$$

Weekly BW was recorded and BCS (scale of 1 to 10 , where 1 is emaciated and 10 obese; Roche et al., 2004) was determined, following morning milking or at approximately $0800 \mathrm{~h}$ during the nonlactating period. All BCS assessors were trained and recalibrated at the start of the experiment following the procedures set 
out in Macdonald and Roche (2011). Animal evaluation data for cow breed, breeding worth $(\mathbf{B r} \mathbf{W})$, production worth $(\mathbf{P W})$, and reliability were kindly provided by Livestock Improvement Corporation Ltd. (Hamilton, New Zealand; Table 1). Breeding worth and PW are estimated economic values of a combination of 8 traits as indicators of robustness and production efficiency (Johnson et al., 2018). Breeding worth ranks cows on their expected ability to breed profitable and efficient replacements, whereas PW ranks cows on their lifetime performance (DairyNZ, 2018). In the current study, the economic values are expressed as dollars of net farm income per $5.0 \mathrm{t}$ of DM relative to a 2000-born genetic base cow for the year 2016 so that cows across studies and years are comparable (DairyNZ, 2018). Reliability is a measure of the confidence of an animal's BrW being a measure of their true genetic merit. Breeding worth and PW values were used as proxy measures for milk production potential due to the experimental animals being involved in studies during previous seasons that may have affected their milk yield records.

\section{Weather}

Daily rainfall ( $\mathrm{mm} ; 24$-h period) and daily air temperature $\left({ }^{\circ} \mathrm{C}\right.$; recorded at $0900 \mathrm{~h}$ ) data were retrieved from The National Climate Database (NIWA, 2018) for the duration of the 4 experiments (Table 1). Data were retrieved from station agent number $26,117\left(37.8^{\circ} \mathrm{S}\right.$, $175.3^{\circ} \mathrm{E}$ ) for the BCS, feed, and zeolite studies and from station agent number $25,222\left(39.6^{\circ} \mathrm{S}, 174.3^{\circ} \mathrm{E}\right)$ for the NSAID study (NIWA, 2018). The distance from the climate station to the study site for the BCS, feed, and zeolite studies is $\sim 3 \mathrm{~km}$, and for the NSAID study the distance is $<1 \mathrm{~km}$.

\section{Statistical Analysis}

Each cow was assigned to a group by concatenating study and treatment from the parent experiments.
Statistical analyses were performed using SAS 9.4 (SAS Institute Inc., Cary, NC). Unstructured and compound symmetry covariance structures were tested for all mixed models and that with the lowest Akaike's information criterion value was used.

\section{Milk, BW, BCS, and Parity Data}

Means and SD for daily yields of milk and ECM for 1 to 35 DIM, and for pre- $(-5$ to $-1 \mathrm{wk})$ and postcalving (1 to 5 wk) BCS and BW were obtained using the PROC MEAN procedure. Covariate precalving BCS (cBCS) was determined as the BCS recorded for individual cows at 5 wk precalving. Parity was grouped as follows: parity $2-3(\mathrm{n}=201)$, parity $4-5(\mathrm{n}=70)$, parity 6-7 $(\mathrm{n}=26)$, and parity $8+(\mathrm{n}=13)$. Repeated measures ANOVA (PROC MIXED) were undertaken to determine the effect of breed and parity on yields of milk and ECM including breed, cBCS, parity, and group as fixed and cow as random effects, respectively.

\section{Behavioral Parameters}

Number of records, means, and SD for the daily number of LB and mean LB duration recorded by the IceQube and IceTag devices were calculated for all cows from -21 to $34 \mathrm{~d}$ relative to calving using PROC SUMMARY in SAS (Supplemental Table S2; https:// doi.org/10.3168/jds.2018-16045). In the current study, based on previously determined thresholds for IceRobotics sensors, LB $<33$ s (Kok et al., 2015) and $\leq 2$ min (Mattachini et al., 2013) were discarded from the raw data recorded by the IceQube and IceTag devices, respectively.

\section{Overall, Group, and Individual Cow Means and SD}

Daily means and SD were obtained for each experimental day on a per-cow basis, from which the overall

Table 1. Mean, SD, minimum, and maximum for 14,942 experimental days of $311 \mathrm{cow}$ parities

\begin{tabular}{lcccc}
\hline Parameter $^{1}$ & Mean & SD & Minimum & Maximum \\
\hline cBCS $^{2}$ & 4.73 & 0.52 & 3.75 & 5.75 \\
$\mathrm{PW},{ }^{3} \$ / 5$ t of DM & 110 & 82.6 & -109 & 362 \\
$\mathrm{PW}$ reliability, $\%$ & 91.0 & 8.18 & 51.9 & 95.7 \\
$\mathrm{BrW},{ }^{3} \$ / 5$ t of DM & 111 & 40.5 & -34.0 & 209 \\
BrW reliability, ${ }^{3} \%$ & 52.2 & 2.57 & 37.7 & 59.9 \\
Rainfall, mm & 2.75 & 6.27 & 0.00 & 52.6 \\
Air temperature, ${ }^{4} \mathrm{C}$ & 8.38 & 3.48 & -0.90 & 16.5 \\
\hline
\end{tabular}

${ }^{1}$ Production worth (PW), breeding worth (BrW), and covariate precalving body condition score (cBCS).

${ }^{2}$ Body condition score on a 1 to 10 scale (Roche et al., 2004) at 5 wk precalving.

${ }^{3}$ Genetic merit (New Zealand Animal Evaluation Ltd., Hamilton, New Zealand). Expressed as dollars of net farm income per $5 \mathrm{t}$ of DM relative to a 2000-born genetic base cow for the year 2016 .

${ }^{4}$ Air temperature recorded at $0900 \mathrm{~h}$. 
means and group means were calculated using the PROC MEAN procedure for lying time, LB, mean LB duration, and number of steps for -21 to $34 \mathrm{~d}$. A total of 14,942 d were available for analysis.

\section{Average Changes in Behavior Across Days}

Relationships between lying parameters and daily number of steps, and day were examined by piecewise regression analysis (PROC NLIN) to determine the breakpoints where the most significant changes in behavior occurred by day relative to calving. Starting parameters were estimated for each time period by applying simple linear regressions at multiple time points and investigating the model fit as determined by the square root of mean square error and adjusted R-square. The starting parameters from the models with the best fit were then used to fit the piecewise regression model. These breakpoints output by the model were rounded to the nearest whole day, and subsequently, the data were split into 4 periods according to the behavior of interest. To determine whether cows changed their behavior across days, multiple regression analyses were undertaken using PROC MIXED to determine the effect of day for all 4 behavior measures (daily lying time, daily LB, mean LB duration, and number of steps) during the 4 periods determined from the piecewise regression analysis. For all regression analyses, the intercept was tested for difference from zero, to determine whether behavior changed on average across days. Fixed effects of breed, parity, cBCS, PW, BrW, and group were included to account for possible differences relating to the behaviors of interest because they have been shown to affect behavior. Cow was included as a random effect. The $\mathrm{PW}$ and $\mathrm{BrW}$ parameters were included in the multiple regression model per 10-unit increase. Because cows were outdoors and the experimental periods (across $4 \mathrm{yr}$ ) were different for the studies, rainfall and air temperature and their interaction were evaluated and included in the model (Hendriks et al., 2019). Variables were checked for multicollinearity; however, no variables were highly correlated or had variance inflation factors greater than 10. Descriptive statistics for descriptive variables presented in Table 1 were undertaken using PROC MEAN procedure.

\section{Effect of Period on Behavior Parameters}

Additional repeated measures ANOVA (PROC MIXED) were undertaken to summarize daily and 24-h behavior immediately pre- and postcalving (i.e., PRE, -21 to $-3 \mathrm{~d}$, and POST, 3 to $21 \mathrm{~d}$ ) and on the day of calving (d 0). Farm staff collected newborn calves and their dams once daily, and therefore, there may be a discrepancy of up to $24 \mathrm{~h}$ for the recording of the day of calving. Daily lying time, daily LB, mean LB duration, and number of steps were calculated for 3 periods. The effect of period on the behavior parameters were analyzed using a repeated measures ANOVA (PROC MIXED) with breed, cBCS, parity, group, period, and interactions between group and period as fixed and cow as random effects, respectively. The overall cBCS, breed, parity, and interactive breed by parity effects on lying behavior were analyzed using a repeated measures ANOVA (PROC MIXED), however, are not reported because the effects were not significant at the level $P<0.05$. The effects of parity and interactive parity by period on number of steps were analyzed during the 4 periods, generated from the piecewise regression described above, using a repeated measures ANOVA (PROC MIXED) with cBCS, breed, parity, period, and the interactions between parity and period as fixed and cow as random effects, respectively. There was no overall cBCS, breed, or interactive breed by parity effect on daily number of steps taken in the current study.

\section{Effect of Period and Time on Behavior Parameters}

For the 24-h data, time was divided into 4-h blocks (i.e., 0200-0559 h, 0600-0959 h, 1000-1359 h, 1400$1759 \mathrm{~h}, 1800-2159 \mathrm{~h}, 2200-0159 \mathrm{~h}$ ) for each of the 3 aforementioned periods. The effect of period and time and their interactions on the behavior parameters were analyzed using a repeated measures ANOVA (PROC MIXED) with breed, cBCS, parity, group, period, and interactions between group and period as fixed and cow as random effects, respectively. All repeated measures ANOVA models were pairwise comparison adjusted using Tukey-Kramer. Means and standard error of the mean were obtained using PROC MEAN procedure for lying time $(\mathrm{min} / \mathrm{h})$ and number of steps (steps/h) on an hourly basis according to time stamp to generate 24-h data for the periods PRE, POST, and d 0 .

\section{RESULTS}

Mean and SD for milk yield and ECM yield were 24.1 $\pm 4.8 \mathrm{~kg} / \mathrm{cow}$ per day. Mean and SD of precalving BCS and BW were $4.7 \pm 0.5$ and $548 \pm 65 \mathrm{~kg}$, respectively, and postcalving BCS and BW were $4.4 \pm 0.4$ and 485 $\pm 55 \mathrm{~kg}$, respectively. A brief description of parameters included in the data set from the 4 experiments used for statistical analysis is provided in Table 1. Mean milk yield was 24.6 and $20.5 \mathrm{~kg} /$ cow per day for the $\mathrm{HF}$ and HF $\times \mathrm{J}$ cows, respectively $(P<0.01)$ for the first 35 DIM. Mean ECM yield was $26.3 \mathrm{~kg} / \mathrm{cow}$ per day and 
$23.4 \mathrm{~kg} /$ cow per day $(P=0.06)$. There was no parity or parity by breed effect on milk yield and ECM yield for the first 35 DIM in the current study.

\section{Overall, Group, and Individual Cow Means, and SD}

Lying time was normally distributed, and the mean and SD across all of the groups for daily lying time was $8.83 \pm 2.45 \mathrm{~h} / \mathrm{d}$ and for daily LB was $8.50 \pm 3.75$ no. $/ \mathrm{d}$ for the period -21 to $34 \mathrm{~d}$ relative to calving. The group means for daily lying time and daily LB varied from 7.94 to $9.69 \mathrm{~h} / \mathrm{d}$ and 7.43 to 9.71 no./d, respectively. For daily lying time and daily $\mathrm{LB}$, individual cow means varied from 5.77 to $12.6 \mathrm{~h} / \mathrm{d}$ and 5.02 and 23.1 no./d, respectively (Figure 1a and $1 \mathrm{~b}$ ). The mean and SD across all of the groups for mean LB duration was $66.3 \pm 26.2 \mathrm{~min} /$ bout, and the group means varied from 55.4 to $76.0 \mathrm{~min} /$ bout, whereas individual cow means varied from 21.4 to $113 \mathrm{~min} /$ bout (Figure 1c). The mean and SD across all groups for daily number of steps was 3,805 $\pm 1,664$ steps/d and the group means varied from 3,244 to 4,560 steps/d, whereas individual cow means varied from 1,638 to 6,065 steps/d (Figure 1d). The variation among cows differed from group to group; for example, the SD across groups for daily lying time varied from 2.25 to $3.28 \mathrm{~h} / \mathrm{d}$, daily $\mathrm{LB}$ varied from 2.93 to 7.06 no./d, and mean LB duration varied from 22.0 to $32.5 \mathrm{~min} /$ bout. Similarly, the SD across groups for daily number of steps varied from 1,138 to 2,147 steps/d.

\section{Effect of Period on Behavior Parameters}

Precalving, cows spent a greater amount of time lying with longer LB durations than postcalving, although the number of LB was statistically but not biologically different (Table 2). On d 0, the time spent lying was lower, LB durations shorter, and number of LB higher compared with PRE and POST periods. On d 0, cows were more active than during the PRE period, as indicated by the greater number of steps taken (Table 2). The highest activity levels, as indicated by the number of steps taken, occurred postcalving.

Daily number of steps taken was higher in the parity 2 to 3 cows compared with the parity 6 to 7 and $8+$ cows, which were not different from each other during the period -2 to $0 \mathrm{~d}(P<0.05)$. The daily number of steps taken was also higher in the parity 2 to 3 cows compared with the parity $8+$ cows during the period 1 to $5 \mathrm{~d}$ (Figure 2). The cBCS and breed had no overall effect on the daily step count. The effects of cBCS, breed, and parity on lying behavior are not reported because these effects were not significant in our study.

\section{Average Changes in Behavior Across Days}

The multiple regression models investigated the average change in lying behavior and activity during 4 periods according to the behavior of interest (Table 3). Daily lying time was associated with day relative to calving for all periods relative to calving for all periods $(P<0.05)$, except -21 to -3 d. Daily lying time declined from $3 \mathrm{~d}$ before calving to $0 \mathrm{~d}$ where the lowest lying time occurred and then increased from 0 to $5 \mathrm{~d}$ (Figure 1a; Table 3). After 5 d postcalving, a steady decline in daily lying time and LB duration occurred (slope $=-0.02 \pm 0.01 \mathrm{~h} / \mathrm{d}$ and $-0.34 \pm 0.05 \mathrm{~min} /$ bout, respectively; $P<0.05$; Table 3 ).

The daily LB increased from $2 \mathrm{~d}$ before calving (slope $=5.09 \pm 0.54$ no. $/ \mathrm{d} ; P<0.05)$ and was greatest the day before calving $(-1 \mathrm{~d}$; Figure $1 \mathrm{~b})$ with an associated decline in the mean LB duration during this period, which was shortest on the day before calving (Figure 1c). Daily LB decreased from -1 to $2 \mathrm{~d}$ (slope $=-2.30$ \pm 0.14 no. $/ \mathrm{d} ; P<0.05)$ with an associated increase in the mean LB duration during this period.

The number of steps taken increased substantially from -2 until $0 \mathrm{~d}$ (slope $=860 \pm 47$ steps/d), followed by a further increase in the number of steps taken in the days postcalving ( 2 to $34 \mathrm{~d}$; slope $=37 \pm 3$ steps $/ \mathrm{d}$; Figure 1d and Table 3$)$.

\section{Effect of Period and Time on Behavior Parameters}

The within-day profiles of lying behavior during the PRE, POST, and d 0 periods are presented in Figure 3. The mean sunrise and sunset times across the 4 experiments correspond with 0731 and $1717 \mathrm{~h}$, respectively (Timeanddate.com, 2017). Due to the staggered milking times across the 4 studies, there was no period of zero lying. The greatest increase in the number of steps taken postcalving compared with precalving occurred between 0600 to $0959 \mathrm{~h}$ and 1400 to $1700 \mathrm{~h}$, which coincides with milking times (Table 4).

A significant period by time interaction was observed for all lying behaviors and activity (Table 4). Lying time was reduced across all time intervals during the $\mathrm{d} 0$ and POST period, except from 1000 to $1359 \mathrm{~h}$ where lying time increased compared with the PRE period. Lying time, LB, and LB duration during the day (0600-1759 h) in the d 0 period seemed more stable compared with precalving, where differences were either not significant or changes in behavior were small compared with changes that occurred at night $(2200-0559$ h). For the POST period, the greatest changes in lying time occurred during the day between 0600 and $1359 \mathrm{~h}$ (Figure 3; Table 4) compared with the PRE period. The lying 

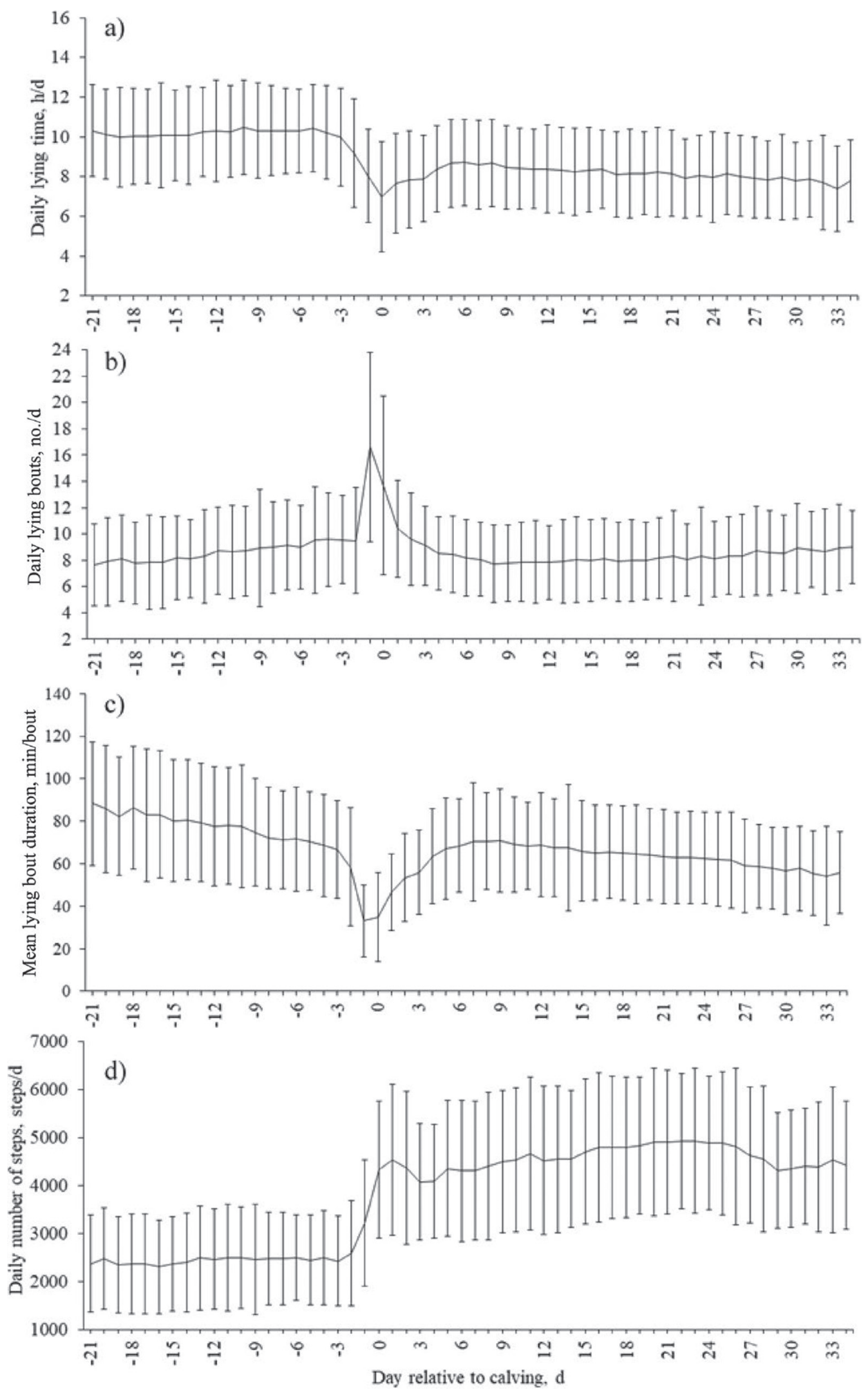

Figure 1. Daily lying time (h/d; a), daily lying bouts (no./d; b), mean lying bout duration (min/bout; c), and number of steps (steps/d; d) during the period -21 to 34 d relative to the day of calving (d 0). Vertical bars represent SD of the sample population. 


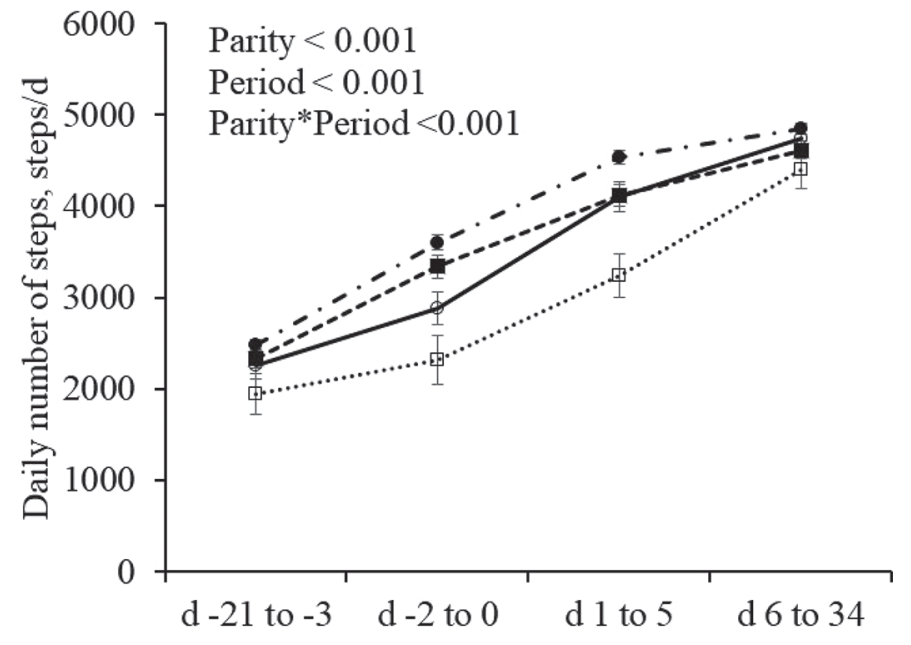

Figure 2. Interaction between parity and period in mean daily number of steps (steps/d) during 4 periods relative to calving $(-21$ to $-3 \mathrm{~d},-2$ to $0 \mathrm{~d}, 1$ to $5 \mathrm{~d}$, and 6 to $34 \mathrm{~d}$ ). Parity 2 to 3 (filled circles), parity 4 to 5 (filled squares), parity 6 to 7 (open circles), and parity $8+$ (open squares). Vertical bars represent SEM.

time declined between 0600 and $0959 \mathrm{~h}(-46.6 \%)$ and increased (+91.9\%) between 1000 and 1359 h; however, LB duration increased during both time intervals in the POST compared with PRE period. The number of steps across all time intervals increased during the POST period, except from 1000 to $1359 \mathrm{~h}$ where fewer steps were taken, compared with the PRE period.

\section{DISCUSSION}

Changes in behavior may be a result of cow, management, or physiological factors. We have quantified the lying behavior and activity of transition dairy cows in a rotational grazing system, including changes to the temporal profiles for lying behavior and activity. Lying behavior and activity, as measured by number of steps taken, changed substantially during the days immediately before and after calving. Temporal profiles for lying behavior and activity indicate that grazing cows follow a similar pattern of lying behavior and activity throughout the day across the transition period. However, the magnitude of these changes was not constant across the transition period. Variation among individual cow means within groups was greater than the variation among the overall group means for lying behavior and activity. Large individual variation in the behavior of individual cows grouped together is an important consideration. The results of this study provide evidence of effects of cow, management, and physiological factors on lying behavior and activity of grazing cows.

\section{Lying Behavior Is Different Under Different Systems}

Adequate daily lying time is regarded as an important metric for the welfare of domesticated animals (Munksgaard and Simonsen, 1996). However, changes in daily lying time may be a result of external factors, such as housing system, management, physiological state, or diet (Munksgaard et al., 2005), and may not be indicative of changes to welfare state. Daily lying time and daily LB were 13 to $28 \%$ and 30 to $44 \%$ less, respectively, in our study of grazed cows than what has been reported for housed cows during the pre- and postcalving periods (Huzzey et al., 2005; Calderon and Cook, 2011; Piñeiro et al., 2019). However, this result appears to be typical for cows at pasture where the daily precalving lying time $(10.3 \mathrm{~h} / \mathrm{d})$ in our study was similar to the value reported for cows moved from housing to pasture precalving (10.3 h/d; Rice et al., 2017). The daily postcalving lying time $(8.58 \mathrm{~h} / \mathrm{d})$ was also within the range of typical values presented for grazing dairy cows (7.50-8.50 h/d, Sepúlveda-Varas et al., 2014). The greater daily lying time in housed systems both pre- and postcalving could be a result of external factors, such as easier feed accessibility and prehension than the competitive features of grazing (Munksgaard et al., 2005; Sepúlveda-Varas et al., 2014). Greater daily lying time postcalving could also be a result of less time spent walking to and from the milking parlor (Huzzey et al., 2005; Sepúlveda-Varas et al., 2014). Despite the

Table 2. Daily lying time (h/d), daily lying bouts (LB; no./d), mean LB duration (min/bout), and number of steps (steps/d) for -21 to $-3 \mathrm{~d}$ (PRE) and 3 to $21 \mathrm{~d}$ (POST) relative to the day of calving (d 0) of transition dairy cows

\begin{tabular}{lccccc}
\hline & \multicolumn{3}{c}{ Period } & & \\
\cline { 2 - 4 } Parameter & PRE & d 0 & POST & SED & $P$-value \\
\hline Daily lying time, h/d & $10.3^{\mathrm{a}}$ & $7.25^{\mathrm{c}}$ & $8.58^{\mathrm{b}}$ & 0.14 & $<0.001$ \\
Daily LB, no./d & $8.15^{\mathrm{b}}$ & $12.9^{\mathrm{a}}$ & $7.74^{\mathrm{c}}$ & 0.21 & $<0.001$ \\
LB duration, min/bout & $77.3^{\mathrm{a}}$ & $39.1^{\mathrm{c}}$ & $69.1^{\mathrm{b}}$ & 1.62 & $<0.001$ \\
Daily number of steps, steps/d & $2,289^{\mathrm{c}}$ & $4,105^{\mathrm{b}}$ & $4,424^{\mathrm{a}}$ & 60 & $<0.001$ \\
\hline
\end{tabular}

${ }^{{ }^{\mathrm{ac}} \mathrm{C}}$ Means with different superscripts are significantly different at the $5 \%$ confidence level.

${ }^{1} \mathrm{SED}=$ standard error of the difference. 
time spent lying by grazing cows being lower compared with housed cows, it is not possible from this study to determine whether this compromises their welfare; however, it probably means that the time budgets of cows should be derived within systems if they are to be useful benchmarks for animal welfare.

Table 3. Regression coefficient (estimate; SE in parentheses) for parameters influencing daily lying time (h/d), daily lying bouts (LB; no./d), mean LB duration (min/bout), and number of steps (steps/d) during 4 periods within the period -21 to $34 \mathrm{~d}$ relative to the day of calving (0 d) of transition dairy cows

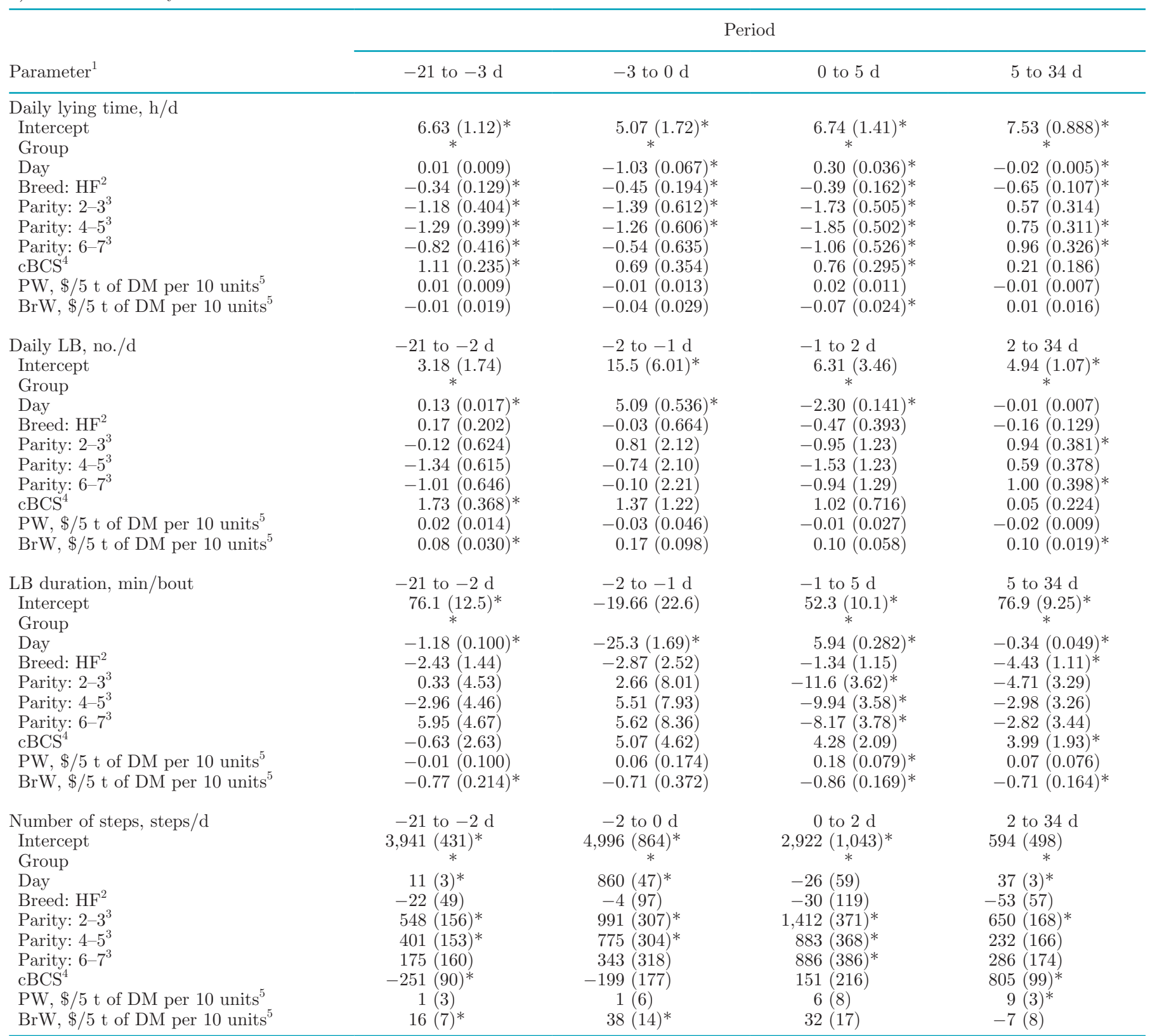

${ }^{1}$ Factors: covariate precalving body condition score (cBCS), production worth $(\mathrm{PW})$, and breeding worth $(\mathrm{BrW})$.

${ }^{2}$ Breed [Holstein-Friesian $(\mathrm{HF}) \times$ Jersey $\left.=0\right]$ is the reference group for breed effects; ${ }^{*} P<0.05$; slope is different from reference group for classification variable.

${ }^{3}$ Parity $(8+=0)$ is the reference group for parity effects; $* P<0.05$; slope is different from reference group for classification variable.

${ }^{4}$ Body condition score on a 1 to 10 scale (Roche et al., 2004) at 5 wk precalving.

${ }^{5}$ Genetic merit (New Zealand Animal Evaluation Ltd., Hamilton, New Zealand). Expressed as dollars of net farm income per $5 \mathrm{t}$ of DM relative to a 2000-born genetic base cow for the year 2016 per 10-unit increase.

$* P<0.05 ;$ slope different from 0 or intercept different from 1. 
Table 4. Lying time $(\mathrm{min} / \mathrm{h})$, lying bouts $(\mathrm{n} / \mathrm{h})$, mean lying bout duration (min/bout), and number of steps (steps/h) across 4 hourly time intervals during 3 periods: -21 to $-3 \mathrm{~d}$ (PRE) and 3 to $21 \mathrm{~d}$ (POST) relative to the day of calving ( $\mathrm{d}$ ) of transition dairy cows

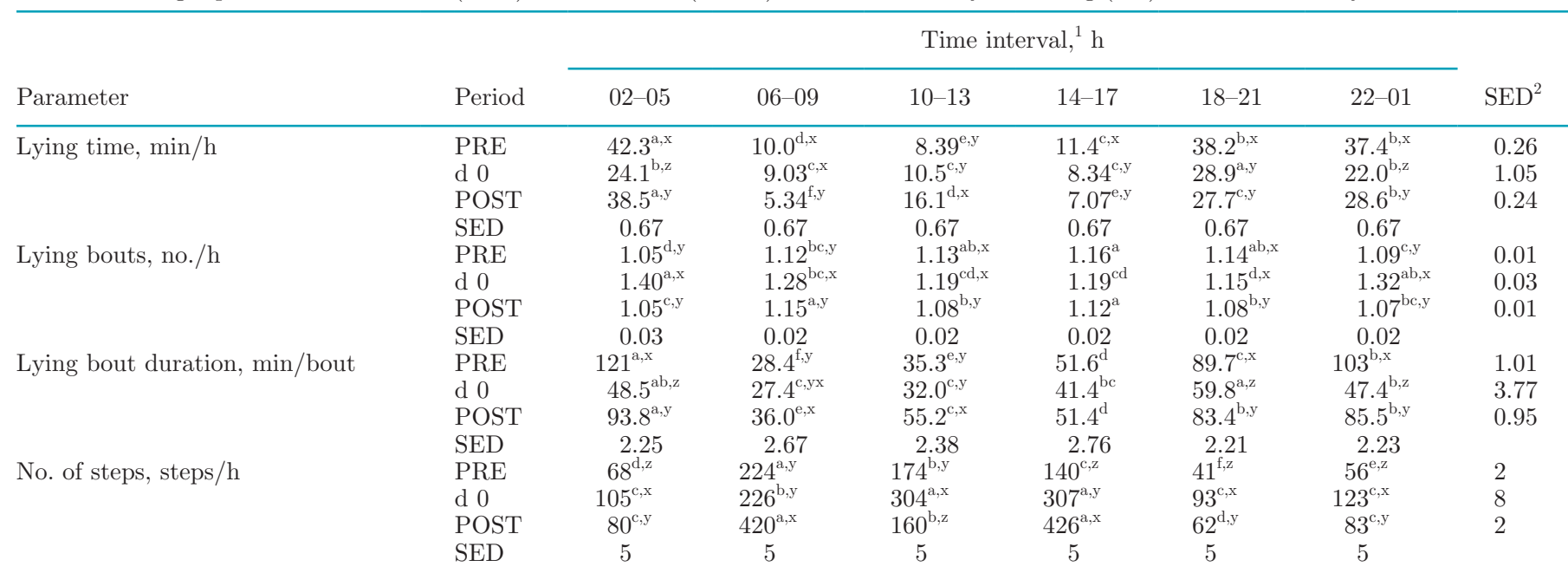

${ }^{\mathrm{a}-\mathrm{f}}$ Means with different superscripts are significantly different at the $5 \%$ confidence level within a row.

${ }^{\mathrm{x}-\mathrm{z}}$ Means with different superscripts are significantly different at the $5 \%$ confidence level within a column.

${ }^{1}$ Time intervals include data within each hour specified (e.g., 22-05 covers the period 2200 to $0559 \mathrm{~h}$ ).

${ }^{2} \mathrm{SED}=$ standard error of the difference.

\section{Cow and Farm Factors Affect Lying Behavior and Activity}

Farm-specific factors such as time spent waiting to be milked (Beggs et al., 2018), wintering system (Al-
Marashdeh et al., 2019), weather (Hendriks et al., 2019), and other management factors need to be considered when comparing behavior measurements from different farms or groups of animals. In the current study, the groups were managed similarly across the studies

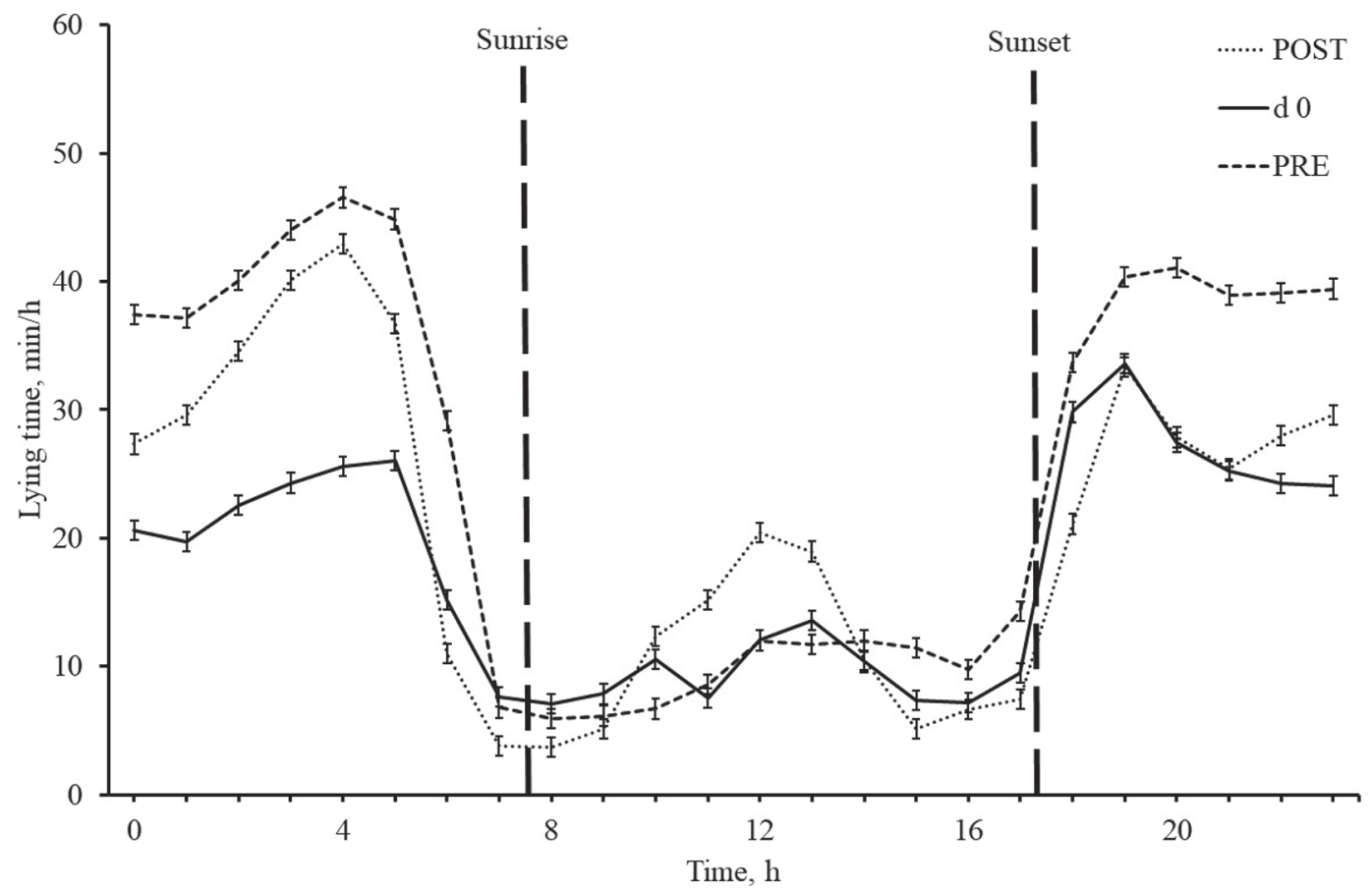

Figure 3. Temporal pattern of grazing dairy cow lying time $(\mathrm{min} / \mathrm{h})$ during the period -3 to $-21 \mathrm{~d}$ (PRE) and 3 to $21 \mathrm{~d}$ (POST) relative to the day of calving (d 0). Vertical bars represent SEM. Dashed vertical lines represent sunrise $(0731 \mathrm{~h})$ and sunset $(1717 \mathrm{~h})$. 
with differences due to studies undertaken across different years, in different locations, with differences in weather and time spent engaged in activities associated with milking. However, despite these differences, the variation among the overall group means was less than the range of means among individual cows within the groups, in agreement with the findings of Ito et al. (2009). Several factors have been suggested as drivers of the larger variation among individual cows compared with variation among herds. It was suggested that individual variation is influenced by an animal's social ranking and variation might be more marked in highly competitive environments (Phillips and Rind, 2001; Ito et al., 2009). In housed cows, competition for space to lie down in freestalls could limit the lying behavior of some cows (Ito et al., 2009), whereas in dairy cows on pasture, competition to lie down may be less likely to disrupt normal lying behavior due to higher space availability (Phillips and Rind, 2001). However, a grazing environment might be more conducive to competition for access to feed and this may disrupt normal lying behavior in some cows, whereas in housed cows, competition for feed may be less likely to influence lying behavior where feed is available ad libitum (Phillips and Rind, 2001). Understanding how social ranking and competition and motivation for access to different resources may disrupt normal lying behavior in some cows and as a potential cause of individual variation in both housed and grazing dairy cows requires further investigation.

Interestingly, the variation among individual cows and farms was greater in the study by Ito et al. (2009) where 43 commercial dairy farms were recruited for the study, compared with the current study. Ito et al. (2009) reported a difference in the range of means for individual cows of $15.3 \mathrm{~h} / \mathrm{d}$ and $27 \mathrm{no} . / \mathrm{d}$ for daily lying time and LB and $342 \mathrm{~min} /$ bout for the mean LB duration among individual housed cows. In the current study, the range was smaller where the difference in the range of means for individual grazing cows for daily lying time, LB, and LB duration was $6.83 \mathrm{~h} / \mathrm{d}, 18.1$ no./d, and $91.6 \mathrm{~min} /$ bout, respectively. In the study by Ito et al. (2009), cows were housed indoors on a range of bedding materials, and the farms recruited included 2 and 3 times daily milking, as well as once and twice daily feeding. The greater variation may be due to large variation in management across farms and in part, due to a larger sample size compared with the current study. The large individual variation in lying behaviors and daily step counts of cows grouped together is an important consideration if benchmarks are established as indicators of welfare, particularly for cows managed under different conditions.
Behaviors expressed may also differ due to cow factors; however, limited studies have investigated both pre- and postcalving lying behavior and activity and the influence of breed, parity, and BCS in grazing dairy cows. Cows in the current study were multiparous and approaching their 2 nd to 11 th parity. In the current study, increasing parity was associated with lower step counts during the period immediately before and after calving. Duncan and Meyer (2019) reported no effect of parity on step count in prepartum beef cows and heifers, but only reported data for $3 \mathrm{~d}$ prepartum. To our knowledge, this is the first study that has reported differences in step count during the transition period due to parity, although this was largely driven by the older cows (parity $6+$ ) in the study. There were no differences in lying behaviors due to parity. Whereas other studies have reported associations between parity and behavior when comparing primiparous with multiparous cows (Calderon and Cook, 2011; Sepúlveda-Varas et al., 2014; Duncan and Meyer, 2019), these results are contrary to the findings of Bewley et al. (2010) where a lack of significance for parity was reported in housed cows. Despite conflicting results, studies should account for parity differences when interpreting behavior data due to differences in social behaviors, milk production, BW, body composition, and DMI between parities that could influence behavioral responses (Phillips and Rind, 2001; Wathes et al., 2007).

In agreement with other studies, in the current study, after accounting for other factors in the model, no significant breed (Stone et al., 2017) or BCS (Bewley et al., 2010) effects were observed on daily lying time, daily LB, mean LB duration, and step count during the transition period. However, studies are limited, and further investigation into potential effects of breed and both pre- and postcalving BCS and changes in BCS on lying behavior and activity across the transition period is warranted.

\section{Physiological State Affects Lying Behavior and Activity}

Changes to an animal's physiological state influence their behavior (Munksgaard et al., 2005), and for a dairy cow, one of the most significant physiological changes that occurs during their life is the change from a nonlactating to a lactating state (Grummer, 1995). On the day of calving, daily lying times were $\sim 3 \mathrm{~h}$ less than precalving $(-21$ to $-3 \mathrm{~d}$ ) and $\sim 1.5 \mathrm{~h}$ less than postcalving ( 3 to $21 \mathrm{~d}$ ). Cows were lying down more frequently, but for shorter periods and the number of steps taken on the day of calving were almost double that taken by the precalving cow. Daily lying time 
decreased substantially from -3 to $0 \mathrm{~d}$ and this was accompanied by an increase in the number of LB from $-2 \mathrm{~d}$, which peaked at $-1 \mathrm{~d}$ and remained elevated on the day of calving. These changes in behavior around the day of calving are similar to those reported in housed cows (Huzzey et al., 2005; Calderon and Cook, 2011; Jensen, 2012; Kok et al., 2015) and dairy cows on pasture (Black and Krawczel, 2016; Borchers et al., 2017; Rice et al., 2017). Restlessness and discomfort around the calving event are likely to be responsible for the changes in behavior (i.e., repeated lying down and standing up and pacing; Huzzey et al., 2005; Borchers et al., 2017). The increase in step count may also be due to cows walking in search of a place to calve or seeking isolation from the herd (Duncan and Meyer, 2019). Future research should investigate whether the changes in daily lying time, LB, or number of steps taken around the calving event could be used to predict timing of calving in grazing cows.

Daily lying time declined steadily during the postcalving period until d 34, in agreement with Maselyne et al. (2017). In studies under confinement housing, higher energy requirements increasing time spent eating have been attributed to less time lying (Løvendahl and Munksgaard, 2016; Stone et al., 2017) and increasing amounts of milk in the udder leading to discomfort has been attributed as a possible cause for the reduction in lying time (Norring et al., 2012). However, in grazing dairy cows, Tucker et al. (2007) reported the reduction in lying time was more likely due to a time constraint associated with milking. Udder discomfort and increased feeding time may have been responsible, in part, to a reduction in lying time in the highest yielding cows in the current study. However, lying time was likely constrained by a known management change due to time associated with milking (Tucker et al., 2007; Norring et al., 2012; Kok et al., 2017).

Postpartum cows spent less time lying $(\sim 1.5 \mathrm{~h})$, with no change in the number of $\mathrm{LB}$ and took a greater number of steps compared with precalving cows. This is similar to results reported by Huzzey et al. (2005); where an increase in the daily standing time of $\sim 1 \mathrm{~h}$ and no change in the number of standing bouts was apparent postcalving and described as "not surprising" due to increased standing time in the milking parlor and time spent walking to and from the milking parlor. In the current study, the difference in lying time was only slightly more than the time associated with milking ( $\sim 40-90 \mathrm{~min})$, and therefore the lower lying time may have been due to the time constraint associated with milking (Tucker et al., 2007). This is further supported by the increased step count around morning and afternoon milking (0600-0959 and 1400-1759 h) and a reduction in lying time in the current study. The lower lying times postcalving with a concomitant increase in the number of steps taken alongside known changes to management of the lactating cow support that postcalving cows were more active due to increased time spent walking to and from the milking parlor and standing during the milking routine (Kok et al., 2017). The associations and trade-offs between time associated with milking, lying, feeding, and other activities are poorly understood in grazing dairy cows. Further research in this area is needed to understand the consequences of these associations with lying behavior on welfare and health in grazing dairy cows.

\section{Lying Behavior and Activity Is Different Within Days}

Patterns in dairy cow behavior within days may be influenced by the calving event and the onset of lactation. On the day of calving, the largest magnitude of change in daily lying time, daily LB, and LB duration occurred at night between 2200 and $0559 \mathrm{~h}$. On average, the LB frequency was higher but LB duration and lying time were longer and cows took fewer steps at night on the day of calving compared with the daytime. These quite dramatic behavioral changes on the day of calving, particularly at night, may indicate restlessness due to discomfort; however, they might be part of the normal calving process (von Keyserlingk and Weary, 2007). Edwards (1983) reported that when cows were given a choice to calve indoors or in a 1-ha paddock, cows that calved outdoors did so more often when calving at night. In the current study, without exact calving times it is difficult to determine whether the greater changes in behavior at night occurred due to more cows calving during the night.

Cows appeared to alter their behavior within day during the transition period, where postcalving greater changes occurred in the middle of the day. Postcalving lying time was lower during five out of six 4 -h periods during the day compared with precalving, with one exception: lying time increased during the middle of the day in the lactating cow (1000-1359 h). A peak in lying time in the middle of the day has been demonstrated before in housed cows (Schirmann et al., 2012; Kok et al., 2017); however, to our knowledge, this is the first study to demonstrate this in grazing dairy cows postcalving through the presentation of temporal profiles of lying time. The increased lying time in the middle of the day in the postcalving cow may be related to a greater need for rumination following a large postmilking DMI (Gibb et al., 1999; Sheahan et al., 2013), as rumination is often associated with lying down (Schirmann et al., 2012). DeVries et al. (2003) reported that the pattern of lying in lactating grazing dairy cows is inversed with feeding and Sheahan et al. (2013) presented temporal 
profiles for grazing behavior that represented the occurrence of major grazing bouts following sunrise and before sunset (i.e., crepuscular feeding). This temporal profile for grazing behavior is consistent with the inverse of the temporal profile for lying presented in the current study. This, in conjunction with the substantial increase in the number of steps taken across all periods and, in particular, after the a.m. and p.m. milking, supports the premise that the postcalving cow is more active at the expense of lying time or idling (DohmeMeier et al., 2014); however, trade-offs between lying, feeding, ruminating, and milking activities require further investigation.

\section{CONCLUSIONS}

The results indicate that changes in dairy cow behavior during the transition period are similar across production systems; however, absolute values are different, are highly variable among individual cows and can be influenced by cow, physiological, and management factors. Daily lying time, daily LB, LB duration, and number of steps taken were substantially altered at the time of the calving event. Postcalving cows took more steps and spent less time lying down compared with precalving cows, and this appeared to be a direct consequence of activity associated with twice daily milking. For this reason, understanding the effects of cow, physiological, and management factors on changes in behavior and activity, and how grazing dairy cows prioritize certain behaviors is important to take into consideration when using behavior as an indicator of health or welfare. Information available via activity monitors may contribute to the improvement of individual management of transition dairy cows and this research provides a benchmark for typical lying behavior during the transition period in grazing systems.

\section{ACKNOWLEDGMENTS}

This work was funded by New Zealand dairy farmers through DairyNZ Inc. (project number RD1405) and by the Ministry of Business, Innovation and Employment through the research partnership "Pillars of a Competitive and Responsible Dairy System: Improved Longevity and Reproductive Performance" (contract number DRCX1302).

\section{REFERENCES}

Al-Marashdeh, O., K. C. Cameron, R. H. Bryant, A. Chen, B. McGowan, C. Gillé-Perrier, P. Carey, J. Chrystal, S. Hodge, and G. R. Edwards. 2019. Effects of surface type in an uncovered standoff pad system on comfort and welfare of non-lactating dairy cows during winter. Appl. Anim. Behav. Sci. 211:17-24. https://doi .org/10.1016/j.applanim.2018.11.001.

Beggs, D. S., E. C. Jongman, P. E. Hemsworth, and A. D. Fisher. 2018. Implications of prolonged milking time on time budgets and lying behavior of cows in large pasture-based dairy herds. J. Dairy Sci. 101:10391-10397. https://doi.org/10.3168/jds.2018-15049.

Bewley, J. M., R. E. Boyce, J. Hockin, L. Munksgaard, S. D. Eicher, M. E. Einstein, and M. M. Schutz. 2010. Influence of milk yield, stage of lactation, and body condition on dairy cattle lying behaviour measured using an automated activity monitoring sensor. J. Dairy Res. 77:1-6.

Black, R. A., and P. D. Krawczel. 2016. A case study of behavior and performance of confined or pastured cows during the dry period. Animals (Basel) 6:E41. https://doi.org/10.3390/ani6070041.

Borchers, M. R., and J. M. Bewley. 2015. An assessment of producer precision dairy farming technology use, prepurchase considerations, and usefulness. J. Dairy Sci. 98:4198-4205. https://doi .org/10.3168/jds.2014-8963.

Borchers, M. R., Y. M. Chang, K. L. Proudfoot, B. A. Wadsworth, A. E. Stone, and J. M. Bewley. 2017. Machine-learning-based calving prediction from activity, lying, and ruminating behaviors in dairy cattle. J. Dairy Sci. 100:5664-5674. https://doi.org/10.3168/jds 2016-11526.

Borchers, M. R., Y. M. Chang, I. C. Tsai, B. A. Wadsworth, and J. M. Bewley. 2016. A validation of technologies monitoring dairy cow feeding, ruminating, and lying behaviors. J. Dairy Sci. 99:74587466. https://doi.org/10.3168/jds.2015-10843.

Calderon, D. F., and N. B. Cook. 2011. The effect of lameness on the resting behavior and metabolic status of dairy cattle during the transition period in a freestall-housed dairy herd. J. Dairy Sci. 94:2883-2894. https://doi.org/10.3168/jds.2010-3855.

DairyNZ. 2018. Breeding worth explained. Accessed Mar 6, 2019. https://www.dairynz.co.nz/media/5789109/nzael_breeding -worth_your_index_feb_2018.pdf.

DeVries, T. J., M. A. von Keyserlingk, D. M. Weary, and K. A. Beauchemin. 2003. Measuring the feeding behavior of lactating dairy cows in early to peak lactation. J. Dairy Sci. 86:3354-3361. https://doi.org/10.3168/jds.S0022-0302(03)73938-1.

Dohme-Meier, F., L. D. Kaufmann, S. Görs, P. Junghans, C. C. Metges, H. A. van Dorland, R. M. Bruckmaier, and A. Münger. 2014. Comparison of energy expenditure, eating pattern and physical activity of grazing and zero-grazing dairy cows at different time points during lactation. Livest. Sci. 162:86-96. https://doi.org/10 .1016/j.livsci.2014.01.006.

Drackley, J. K. 1999. Biology of dairy cows during the transition period: The final frontier? J. Dairy Sci. 82:2259-2273. https://doi .org/10.3168/jds.S0022-0302(99)75474-3.

Duncan, N. B., and A. M. Meyer. 2019. Locomotion behavior changes in peripartum beef cows and heifers. J. Anim. Sci. 97:509-520. https://doi.org/10.1093/jas/sky448.

Edwards, S. A. 1983. The behaviour of dairy cows and their newborn calves in individual or group housing. Appl. Anim. Ethol. 10:191-198.

Gibb, M. J., C. A. Huckle, R. Nuthall, and A. J. Rook. 1999. The effect of physiological state (lactating or dry) and sward surface height on grazing behaviour and intake by dairy cows. Appl. Anim. Behav. Sci. 63:269-287. https://doi.org/10.1016/S0168 -1591(99)00014-3.

Grummer, R. R. 1995. Impacts of changes in organic nutrient metabolism on feeding the transition dairy cow. J. Anim. Sci. 73:28202833.

Hendriks, S. J., C. V. C. Phyn, S.-A. Turner, K. M. Mueller, B. KuhnSherlock, D. J. Donaghy, J. M. Huzzey, and J. R. Roche. 2019. Effect of weather on activity and lying behavior in clinically healthy grazing dairy cows during the transition period. Anim. Prod. Sci. https://doi.org/10.1071/AN18569.

Huzzey, J. M., M. A. G. von Keyserlingk, and D. M. Weary. 2005. Changes in feeding, drinking, and standing behavior of dairy cows during the transition period. J. Dairy Sci. 88:2454-2461. https:// doi.org/10.3168/jds.S0022-0302(05)72923-4. 
IceRobotics Ltd. 2017. Specialist data collection solutions for researchers and educators. Accessed Jan. 20, 2018. http://www.icerobotics .com/wp-content/uploads/2017/05/IceRobotics_Product _Brochure_2017.pdf.

Ito, K., D. M. Weary, and M. A. G. von Keyserlingk. 2009. Lying behavior: Assessing within- and between- herd variation in freestall-housed dairy cows. J. Dairy Sci. 92:4412-4420. https://doi .org/10.3168/jds.2009-2235.

Jensen, M. B. 2012. Behaviour around the time of calving in dairy cows. Appl. Anim. Behav. Sci. 139:195-202. https://doi.org/10 .1016/j.applanim.2012.04.002.

Jensen, M. B., L. J. Pedersen, and L. Munksgaard. 2005. The effect of reward duration on demand functions for rest in dairy heifers and lying requirements as measured by demand functions. Appl. Anim. Behav. Sci. 90:207-217. https://doi.org/10.1016/j.applanim .2004.08.006.

Johnson, T., K. Eketone, L. McNaughton, K. Tiplady, J. Voogt, R. Sherlock, G. Anderson, M. Keehan, S. R. Davis, R. J. Spelman, D. Chin, and C. Couldrey. 2018. Mating strategies to maximize genetic merit in dairy cattle herds. J. Dairy Sci. 101:4650-4659. https://doi.org/10.3168/jds.2017-13538.

Kok, A., R. J. van Hoeij, B. J. Tolkamp, M. J. Haskell, A. T. M. van Knegsel, I. J. M. de Boer, and E. A. M. Bokkers. 2017. Behavioural adaptation to a short or no dry period with associated management in dairy cows. Appl. Anim. Behav. Sci. 186:7-15. https://doi .org/10.1016/j.applanim.2016.10.017.

Kok, A., A. T. M. van Knegsel, C. E. van Middelaar, H. Hogeveen, B. Kemp, and I. J. M. de Boer. 2015. Technical note: Validation of sensor-recorded lying bouts in lactating dairy cows using a 2-sensor approach. J. Dairy Sci. 98:7911-7916. https://doi.org/10.3168/ jds.2015-9554.

Løvendahl, P., and L. Munksgaard. 2016. An investigation into genetic and phenotypic variation in time budgets and yield of dairy cows J. Dairy Sci. 99:408-417. https://doi.org/10.3168/jds.2015-9838.

Macdonald, K., and J. R. Roche. 2011. Condition Scoring Made Easy. 3rd ed. DairyNZ, Hamilton, New Zealand.

Maselyne, J., M. Pastell, P. T. Thomsen, V. M. Thorup, L. Hänninen, J. Vangeyte, A. Van Nuffel, and L. Munksgaard. 2017. Daily lying time, motion index and step frequency in dairy cows change throughout lactation. Res. Vet. Sci. 110:1-3.

Mattachini, G., E. Riva, C. Bisaglia, J. C. A. M. Pompe, and G. Provolo. 2013. Methodology for quantifying the behavioral activity of dairy cows in freestall barns. J. Anim. Sci. 91:4899-4907. https:// doi.org/10.2527/jas.2012-5554.

Matthews, L. R., C. Cameron, A. J. Sheahan, E. S. Kolver, and J. R. Roche. 2012. Associations among dairy cow body condition and welfare-associated behavioral traits. J. Dairy Sci. 95:2595-2601. https://doi.org/10.3168/jds.2011-4889.

Ministry for Primary Industries. 1999. New Zealand Animal Welfare Act. Part 6. Use of animals in research, testing and teaching. Accessed Aug. 20, 2018. http://www.legislation.govt.nz/act/public/ 1999/0142/latest/DLM50499.html?search=sw_096be8ed817c720c _Part +6_25_se\&p=1.

Munksgaard, L., M. B. Jensen, L. J. Pedersen, S. W. Hansen, and L. Matthews. 2005. Quantifying behavioural priorities-Effects of time constraints on behaviour of dairy cows, Bos taurus. Appl. Anim. Behav. Sci. 92:3-14. https://doi.org/10.1016/j.applanim .2004.11.005

Munksgaard, L., and H. B. Simonsen. 1996. Behavioral and pituitary adrenal-axis responses of dairy cows to social isolation and deprivation of lying down. J. Anim. Sci. 74:769-778. https://doi.org/10 $.2527 / 1996.744769 x$.

National Institute of Water and Atmospheric Research (NIWA). 2018. The National Climate Database. Accessed Aug. 16, 2018. https:/ /cliflo.niwa.co.nz/.

Neave, H. W., J. Lomb, M. A. G. von Keyserlingk, A. Behnam-Shabahang, and D. M. Weary. 2017. Parity differences in the behavior of transition dairy cows. J. Dairy Sci. 100:548-561. https://doi.org/ $10.3168 /$ jds.2016-10987.
Nielsen, S. S., M. A. Krogh, and C. Enevoldsen. 2009. Time to the occurrence of a decline in milk production in cows with various paratuberculosis antibody profiles. J. Dairy Sci. 92:149-155. https: //doi.org/10.3168/jds.2008-1488.

Norring, M., A. Valros, and L. Munksgaard. 2012. Milk yield affects time budget of dairy cows in tie-stalls. J. Dairy Sci. 95:102-108.

Phillips, C. J. C., and M. I. Rind. 2001. The effect on production and behavior of mixing uniparous and multiparous cows. J. Dairy Sci. 84:2424-2429.

Piñeiro, J. M., B. T. Menichetti, A. A. Barragan, A. E. Relling, W. P. Weiss, S. Bas, and G. M. Schuenemann. 2019. Associations of pre- and postpartum lying time with metabolic, inflammation, and health status of lactating dairy cows. J. Dairy Sci. 102:3348-3361.

Rice, C. A., N. L. Eberhart, and P. D. Krawczel. 2017. Prepartum lying behavior of Holstein dairy cows housed on pasture through parturition. Animals (Basel) 7:1-9. https://doi.org/10.3390/ ani7040032.

Roche, J. R., P. G. Dillon, C. R. Stockdale, L. H. Baumgard, and M. J. Vanbaale. 2004. Relationships among international body condition scoring systems. J. Dairy Sci. 87:3076-3079. https://doi.org/ 10.3168/jds.S0022-0302(04)73441-4.

Roche, J. R., N. C. Friggens, J. K. Kay, M. W. Fisher, K. J. Stafford, and D. P. Berry. 2009. Invited review: Body condition score and its association with dairy cow productivity, health, and welfare. J. Dairy Sci. 92:5769-5801. https://doi.org/10.3168/jds.2009-2431.

Roche, J. R., E. S. Kolver, and J. K. Kay. 2005. Influence of precalving feed allowance on periparturient metabolic and hormonal responses and milk production in grazing dairy cows. J. Dairy Sci. 88:677-689.

Roche, J. R., K. A. Macdonald, K. E. Schutz, L. R. Matthews, G. A. Verkerk, S. Meier, J. J. Loor, A. R. Rogers, J. McGowan, S. R. Morgan, S. Taukiri, and J. R. Webster. 2013. Calving body condition score affects indicators of health in grazing dairy cows. J. Dairy Sci. 96:5811-5825. https://doi.org/10.3168/jds.2013-6600.

Schirmann, K., N. Chapinal, D. M. Weary, W. Heuwieser, and M. A. von Keyserlingk. 2012. Rumination and its relationship to feeding and lying behavior in Holstein dairy cows. J. Dairy Sci. 95:32123217. https://doi.org/10.3168/jds.2011-4741.

Sepúlveda-Varas, P., D. M. Weary, and M. A. G. von Keyserlingk. 2014. Lying behavior and postpartum health status in grazing dairy cows. J. Dairy Sci. 97:6334-6343. https://doi.org/10.3168/ jds.2014-8357.

Sheahan, A. J., R. C. Boston, and J. R. Roche. 2013. Diurnal patterns of grazing behavior and humoral factors in supplemented dairy cows. J. Dairy Sci. 96:3201-3210. https://doi.org/10.3168/ jds.2012-6201.

Stone, A. E., B. W. Jones, C. A. Becker, and J. M. Bewley. 2017. Influence of breed, milk yield, and temperature-humidity index on dairy cow lying time, neck activity, reticulorumen temperature, and rumination behavior. J. Dairy Sci. 100:2395-2403.

Timeanddate.com. 2017. Hamilton, New Zealand - Sunrise, sunset, and daylength. Accessed Feb. 13, 2018. https://www.timeanddate $. \mathrm{com} / \mathrm{sun} /$ new-zealand/hamilton.

Tucker, C. B., D. E. Dalley, J.-L. K. Burke, and D. A. Clark. 2007. Milking cows once daily influences behavior and udder firmness at peak and mid lactation. J. Dairy Sci. 90:1692-1703.

von Keyserlingk, M. A., and D. M. Weary. 2007. Maternal behavior in cattle. Horm. Behav. 52:106-113.

Wathes, D. C., Z. Cheng, N. Bourne, V. J. Taylor, M. P. Coffey, and S. Brotherstone. 2007. Differences between primiparous and multiparous dairy cows in the inter-relationships between metabolic traits, milk yield and body condition score in the periparturient period. Domest. Anim. Endocrinol. 33:203-225.

Weary, D. M., J. M. Huzzey, and M. A. G. von Keyserlingk. 2009. Board Invited Review: Using behavior to predict and identify ill health in animals. J. Anim. Sci. 87:770-777. 